\title{
PRACTICAL EXPERIENCE WITH WELDING NEW GENERATION STEEL THOR®115 ASSIGNED FOR POWER INDUSTRY
}

\author{
${ }^{1}$ Krzysztof KWIECIŃSKI, ${ }^{2}$ Michał URZYNICOK, ${ }^{3}$ Antonella FERRARA, ${ }^{3}$ Valentina BARSAN \\ ${ }^{1}$ Łukasiewicz - Institute of Welding, Gliwice, Poland, EU, krzysztof.kwiecinski@is.gliwice.pl \\ 2ZELKOT, Koszęcin, Poland, EU, mu@zelkot.pl \\ ${ }^{3} T e n a r i s, D a l m i n e$, Italy, EU, aferrara@tenaris.com, SILZAL@tenaris.com,
}

https://doi.org/10.37904/metal.2020.3527

\begin{abstract}
Very popular and highly employed steel grades such as the $9 \% \mathrm{Cr}$ CSEF steels are limited in terms of service temperature mainly due to capping their steam oxidation resistance capabilities at temperature levels, required by the drive for efficiency increase. For heat-exchangers manufactured from conventional materials, the formation, growth and spallation of oxide scale on the steam side may eventually impair plant operations and damage other downstream components. To address the requirements of the energy market considering these new requirements, Tenaris developed the Tenaris High Oxidation Resistance (THOR®115) CSEF steel grade. Easy weldability is a key property of steel grades and is decisive whether or not a material is adopted by power plant manufacturers. This paper presents the welding experience of THOR $® 115$ grade assigned to power industry. In contribution, results of non-destructive and destructive tests gained during first steps of welding homogenous welded joints are presented.
\end{abstract}

Keywords: THOR®115, welded joints, power plants, microstructure, mechanical properties, steel

\section{INTRODUCTION}

The alloy composition of the CSEF steel grade THOR®115 was developed as an improvement to the popular ASME BPVC edition 2013 grade 91, using similar alloying principles, but aiming at improved performance. The chromium content was increased to improve steam oxidation resistance by promoting the formation of a Cr-rich, compact and passivating scale when exposed to high temperature steam. $\mathrm{Cr}$ also provides solid solution strengthening. In addition the Mo and $\mathrm{Nb}$ contents were lowered, to prevent the formation of unwanted secondary phases, such as Laves and Z-phase, after ageing at service temperature [1].

THOR $₫ 115$ develops a fully tempered martensite microstructure after normalising and tempering. Degenerating long term microstructural stability mechanisms of the CSEF steel family operating at elevated temperature include the Laves and the $Z$ phase. THOR $® 115$ copes with these mechanisms as follows. The appearance of Laves intermetallic compound is avoided due to a reduced Molybdenum content. The appearance of $Z$ phase is delayed exploiting the superior stability of $\mathrm{V}$-rich carbo-nitrides compared to $\mathrm{Nb}$-rich ones, as the kinetics of the detrimental $\mathrm{Z}$ phase is faster in case of $\mathrm{Nb}$-rich carbides than in those rich in $\mathrm{V}$. As a consequence, the THOR®115 alloy aims at a much higher $\mathrm{V}: \mathrm{Nb}$ ratio than other CSEF steel grades. Consequently it shows no $\mathrm{Z}$ phase in the microstructure of aged material of up to $15 \mathrm{kh}$ when exposed to temperatures in the range $600{ }^{\circ} \mathrm{C}$ to $650{ }^{\circ} \mathrm{C}$ [1]. Crept specimen and material sample exposed on field in a Power Plant shows that the appearance of the Z-phase is delayed compared to that of grade 91 or other 11$12 \mathrm{Cr} \%$ steels, thus validating the long term microstructural stability of this material. The solid line the Figure 1 present the onset of Z-phase appearance in 11-12\%Cr steels and grade 91 for service condition characteristic temperature levels as observed by [5]. Aged THOR®115 material represented in Figure 1 as 
dots shows that the first appearance of Z-phase is delayed even when compared to gr. 91, a steel grade with a lower $\mathrm{Cr}$ content.

Another improvement of THOR®115 compared to $9 \% \mathrm{Cr}$ steels is its steam oxidation resistance, due to the increase in $\mathrm{Cr}$ content. Steam oxidation is a steel degradation mechanism, which includes material loss, caused by chemical reactions between iron and oxygen, amplified in boiler components operated at high temperature levels and heavily fluxed by water vapour. The steam oxidation resistance of steel grades can be a limiting factor in determining the lifetime of highly exposed components, resulting in component's thickness reduction. In addition, the oxide scale is significantly less thermal conductive than the base material, causing thermal gradients and potentially creating local hot-spots on the heat-transferring surfaces. Oxide scales may accumulate and produce clogging, therefore choking the working fluid flow [3]. The steam oxidation resistance of THOR®115 has been assessed within different testing campaigns carried out by the Oak Ridge laboratory, while exposing material coupons $(3 \times 15 \times 20 \mathrm{~mm})$ in steam (filtered, deaerated and deionized water with $\sim 0.06 \mu \mathrm{S} / \mathrm{cm}$ conductivity atomized into the furnace) at temperature $600{ }^{\circ} \mathrm{C}, 625^{\circ} \mathrm{C}$ and $650^{\circ} \mathrm{C}$. After each 500-h cycle, material coupon mass changes were measured on a Mettler Toledo scale model XP205 and the specimens were sectioned and polished to examine the oxide thickness and morphology. The same test has been performed on $9 \% \mathrm{Cr}$ as reference. Figure 2 shows the behaviour of the total oxide layer at different temperature for grade 91 and for THOR®115. the thickness of the oxide layer in the case of THORß115 remains constant with the temperature in the range $600{ }^{\circ} \mathrm{C}-650{ }^{\circ} \mathrm{C}$, while for a $9 \% \mathrm{Cr}$ steel an increase in temperature leads dramatically to an increase of the oxide layer [4].

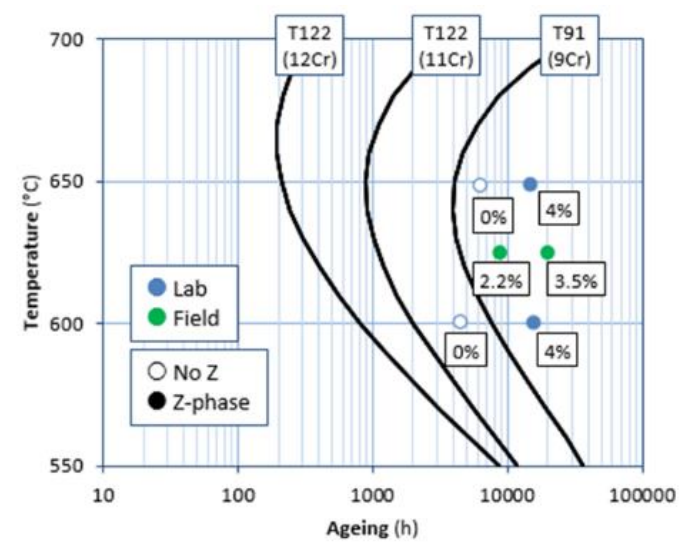

Figure 1 Evolution of $Z$ phase at different ageing conditions - laboratory tests. Timetemperature-precipitation diagrams [2]

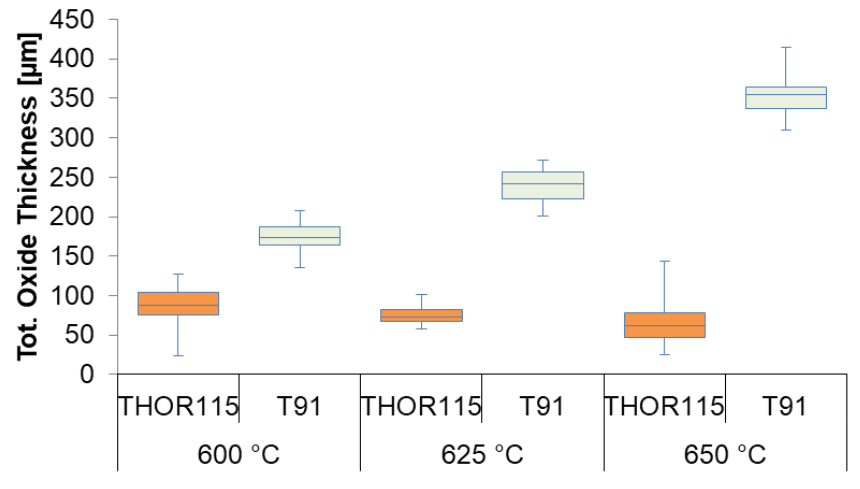

Figure 2 Evolution of total oxide layer after $11 \mathrm{kh}$ of exposure in steam atmosphere for THOR $囚 115$ and grade $91[4]$

In order to validate the steam oxidation resistance of THOR®115, testing under cyclic temperature conditions has been performed since May 2015 as THOR®115 tubes have been installed in a commercially operated HRSG in Italy. The results validate THOR®115 's noticeable steam oxidation resistance when operated under steam temperature cycles of $580-625^{\circ} \mathrm{C}$, a temperature range which is characteristic for modern commercially operated power plants. The results of the field steam oxidation tests are comparable to the ones observed in laboratory [5]. Based on the finding and the internal assessment performed by some HRSG vendors and their experience it can be concluded that THOR $\Omega 115$ doesn't require a corrosion allowance to be added to the integrity based minimum wall thickness calculation, resulting in a total weight decrease of a heat-exchanger made of THOR $® 115$ compared to grade 91 or 92 . The parameters for the production of the welded joint described in the article were selected by the authors on grounds of available publications as well as their own experience [6-10]. The welded joint was produced in „ZELKOT” in Koszecin, Poland. 


\section{OBJECT OF TESTS}

The subject of the study was a pipe $(\varnothing 50.8 \times 10.1 \mathrm{~mm}$ ) made of THOR囚115 steel, manufactured by Tenaris. The chemical composition of the steel is detailed in Table 1. The mechanical properties of THOR®115 steel as delivered are presented in Table 2. The tubes were welded with GTAW in 5G uphill position.

Table 1 Chemical composition of examined steel acc. to MTR

\begin{tabular}{|c|c|c|c|c|c|c|c|c|}
\hline \multicolumn{8}{|c|}{ Contents of chemical elements, wt\% } \\
\hline C & Mn & Si & Cr & Mo & Ni & V & Nb & N \\
\hline 0.09 & 0.47 & 0.15 & 10.78 & 0.51 & 0.15 & 0.24 & 0.034 & 0.0042 \\
\hline
\end{tabular}

Table 2 Mechanical properties of tested steel acc. to producer's quality cert

\begin{tabular}{|c|c|c|c|c|c|}
\hline \multicolumn{6}{|c|}{ Mechanical properties } \\
\hline $\begin{array}{c}\mathbf{R e} \\
\mathrm{MPa}\end{array}$ & $\begin{array}{c}\mathbf{R m} \\
\mathbf{M p a}\end{array}$ & $\begin{array}{l}\mathbf{A} \\
\%\end{array}$ & HV10 & $\begin{array}{c}R_{e} \\
\mathrm{MPa} \\
650^{\circ} \mathrm{C}\end{array}$ & $\begin{array}{c}\mathrm{R}_{\mathrm{m}} \\
\mathrm{MPa} \\
650^{\circ} \mathrm{C}\end{array}$ \\
\hline 615 & 681 & 27.5 & 224 & 214 & 255 \\
\hline
\end{tabular}

The welded joints were made using the TIG (141) method in the PH position (5G from bottom to top according to ASME). Due to the fact that there is currently no dedicated welding consumable for THOR®115 steel, Tenaris recommends using the filler material for steel grade 91 - W CrMo91. In order to check the influence of various additional materials on the quality of welded joints, two other filler metals - S Ni 6082 and EPRI 87 were also used. Table 3 lists the chemical compositions of the used materials.

Table 3 Chemical composition of filler metal acc. to producer's data

\begin{tabular}{|c|c|c|c|c|c|c|c|c|c|c|c|}
\hline \multirow{2}{*}{ Grade } & \multicolumn{10}{|c|}{ Contents of chemical elements, \% } \\
\cline { 2 - 20 } & $\mathbf{C}$ & Mn & $\mathbf{S i}$ & $\mathbf{C r}$ & $\mathbf{N i}$ & $\mathbf{M o}$ & $\mathbf{N b}$ & $\mathbf{T i}$ & $\mathbf{V}$ & $\mathbf{A l}$ & $\mathbf{F e}$ \\
\hline W CrM091 & 0.09 & 0.51 & 0.25 & 9.0 & 0.63 & 0.94 & 0.052 & - & 0.22 & - & rest \\
\hline S Ni 6082 & 0.035 & 2.99 & 0.08 & 20.0 & rest & - & 2.42 & 0.35 & - & - & 1.27 \\
\hline EPRI P87 & 0.11 & 1.55 & 0.16 & 8.52 & rest & 2.02 & 1.09 & - & - & - & 38.8 \\
\hline
\end{tabular}

After welding, according to the pipe manufacturer's recommendations, the welded joints were subjected to stress relief annealing at a temperature of $760^{\circ} \mathrm{C}$ for a period of 60 minutes. After the post weld heat treatment (PWHT), non-destructive tests were performed (VT, PT and RT). These tests were carried out taking into account the quality level B according to PN-EN ISO 5817. After obtaining positive NDT test results, joints were sampled for destructive testing. The scope of destructive testing included: tensile test, bending test, impact tests, macro- and microscopic metallographic tests, hardness measurements.

\section{RESEARCH RESULTS}

Tensile test of the welded joints were performed to determine the tensile strength $(\mathrm{Rm})$ and to verify the results obtained due to the required minimum $\mathrm{Rm}$ value for the parent material (MR), which is $620 \mathrm{MPa}$ for Thor 115 steel (specified by an ASME Code Case 2890 and VdTÜV WB580). The test was carried out in accordance with the requirements of PN-EN 6892-1 and PN-EN ISO 6892-2. The tests were carried out both at room and at elevated temperatures: $600,625,650^{\circ} \mathrm{C}$. The obtained test results are summarized in Figure 3 . Impact test was carried out at ambient temperature $+20^{\circ} \mathrm{C}$ on Charpy $\mathrm{V}$ samples, notched in the weld and in the heat affected zone in accordance with the requirements of PN-EN ISO 148-1 and PN-EN ISO 9016. The criterion 
included in the PN-EN 12952-6 standard specifies the minimum value of the breaking work of samples with a normal cross-section $(10 \times 10 \mathrm{~mm})$ in SWC at $24 \mathrm{~J}$ at ambient temperature, while the PN-EN 10216-2 standard specifies the minimum value breaking work for MR at level $27 \mathrm{~J}$. The tests were carried out on samples with a reduced cross-section $(7.5 \times 10 \mathrm{~mm})$. The results obtained are summarized in Figure 4 . Bending tests were performed in accordance with the requirements of the standards PN-EN ISO 5173. According to the standards, the test criterion is to obtain a bending angle of $180^{\circ}$, without scratches or cracks on the stretched surface of the sample. The results obtained during the tests meet the requirements of the standard.

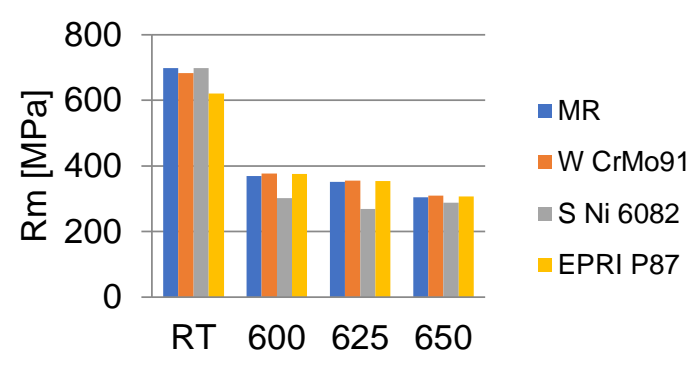

Figure 3 Tensile strength of THORß115 butt welded joints made with differet filler metals

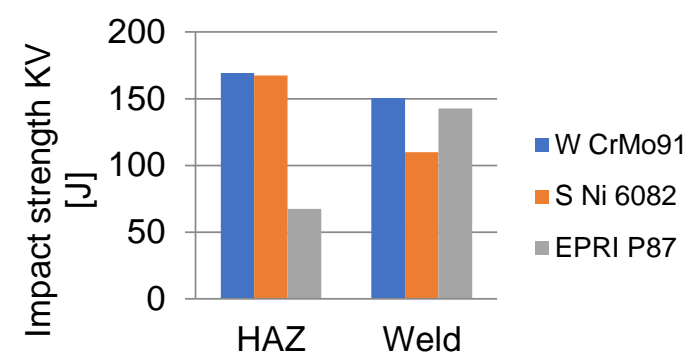

Figure 4 Impact energy THORß115 butt welded joints made with differet filler metals

Hardness measurements were carried out following the requirements of the standards PN-EN ISO 15614-1 and PN-EN 12952-6 PN EN ISO 6507-1 and PN-EN ISO 9015-1. The aforesaid standards define the maximum hardness for martensitic steels at level of $350 \mathrm{HV} 10$. The distribution of hardness measuring points is shown in Figure 5 and the results of the measurements for filler metals W CrMo91, S Ni 6082 and EPRI P87 are presented in Table 4.

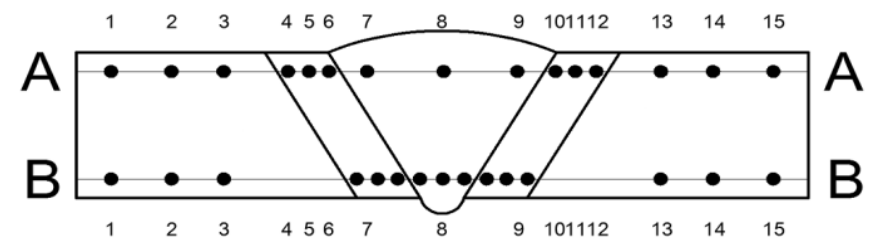

Figure 5 Arrangement of hardness measurement points in tested welded joints

Table 4 Results of THOR囚115 welded joints hardness measurement

\begin{tabular}{|c|c|c|c|c|c|c|c|c|c|c|c|c|c|c|c|c|}
\hline \multirow{2}{*}{ Material } & \multirow{2}{*}{ Line } & \multicolumn{15}{|c|}{ Measurement points } \\
\hline & & 1 & 2 & 3 & 4 & 5 & 6 & 7 & 8 & 9 & 10 & 11 & 12 & 13 & 14 & 15 \\
\hline \multirow{2}{*}{ WCrMo91 } & A & 204 & 206 & 204 & 236 & 273 & 282 & 274 & 274 & 274 & 288 & 288 & 275 & 208 & 212 & 212 \\
\hline & B & 210 & 207 & 207 & 210 & 220 & 225 & 253 & 257 & 258 & 256 & 253 & 247 & 193 & 194 & 199 \\
\hline \multirow{2}{*}{ S Ni 6082} & A & 203 & 203 & 200 & 217 & 245 & 282 & 179 & 158 & 165 & 251 & 275 & 286 & 206 & 207 & 209 \\
\hline & B & 212 & 212 & 213 & 205 & 229 & 255 & 206 & 196 & 189 & 250 & 240 & 231 & 208 & 210 & 213 \\
\hline \multirow{2}{*}{ EPRI P87 } & A & 207 & 211 & 210 & 302 & 295 & 301 & 163 & 162 & 144 & 295 & 305 & 308 & 200 & 206 & 209 \\
\hline & B & 217 & 212 & 203 & 284 & 289 & 287 & 181 & 186 & 187 & 263 & 261 & 254 & 203 & 208 & 209 \\
\hline
\end{tabular}

Metallographic Macroscopic and microscopic tests were carried out following the requirements of the standard PN-EN ISO 17639. A criterion adopted for assessment was the quality level B according to the standard PNEN ISO 5817. Figures 6, 7 and 8 presents the results of macroscopic tests in the form of a photograph of the microstructure of a GTAW butt joint made of steel grade THOR $® 115$ welded with W CrMo91, Inconel 82 and 
EPRI P87 filler metals. The results of the microscopic tests did not show any welding imperfections and confirmed the correct microstructure in all zones. The results in the form of photos and descriptions of structures occurring in the characteristic zones are presented in Figure 9.

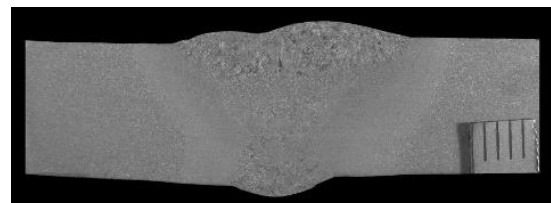

Figure 6 THOR®115 welded with W CrMo91 filler metal; etchant: Adler; quality level:

a

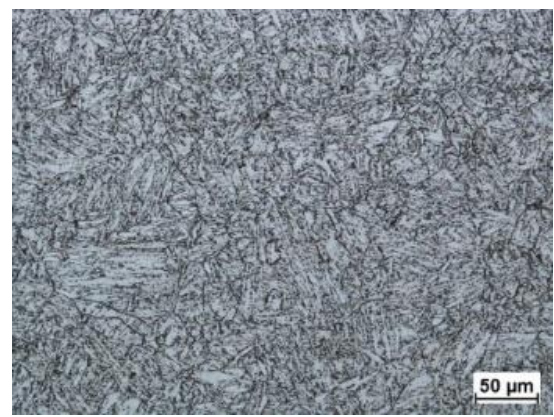

d

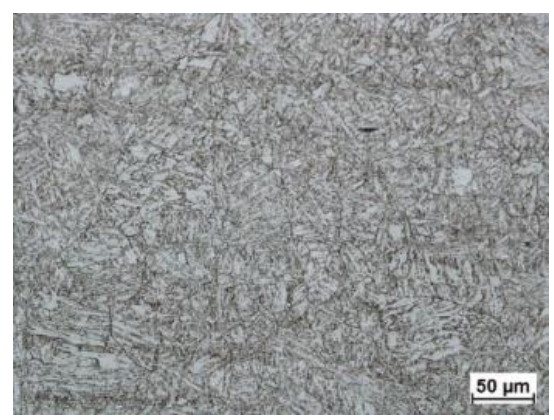

g

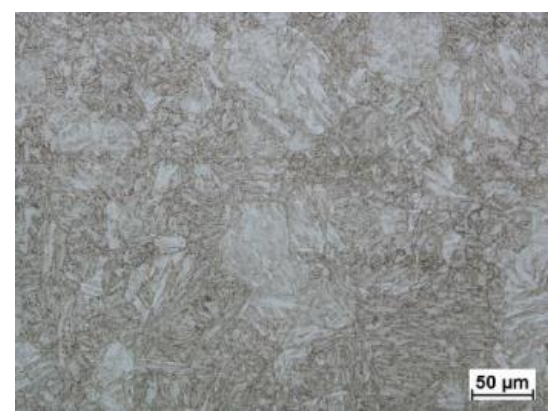

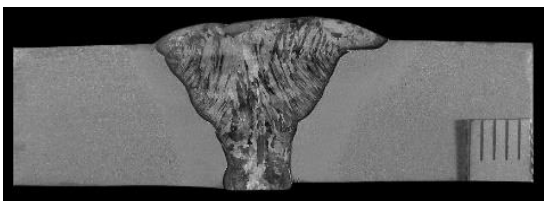

Figure 7 THOR®115 welded with S Ni 6082 filler metal; etchant: Adler; quality level: B b

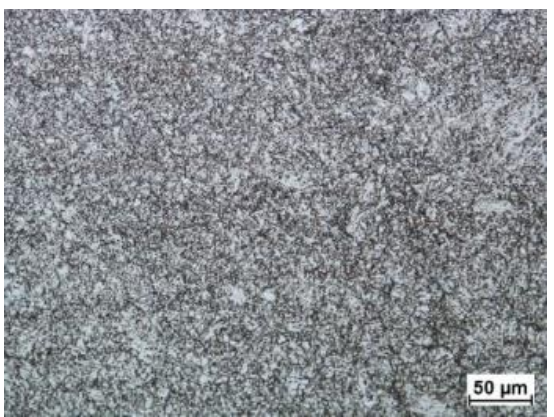

e

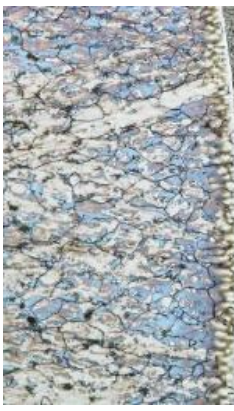

h

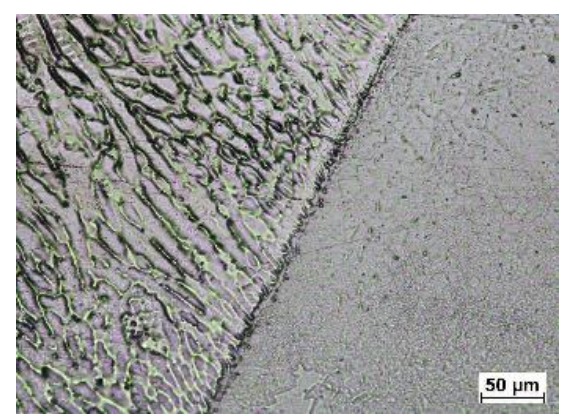

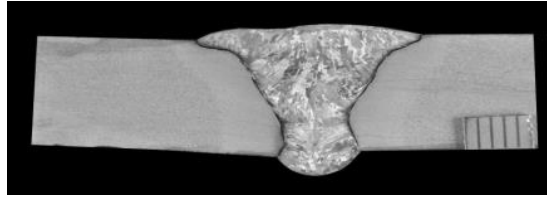

Figure 8 THOR®115 welded with EPRI P87 filler metal; etchant: Adler; quality level: B

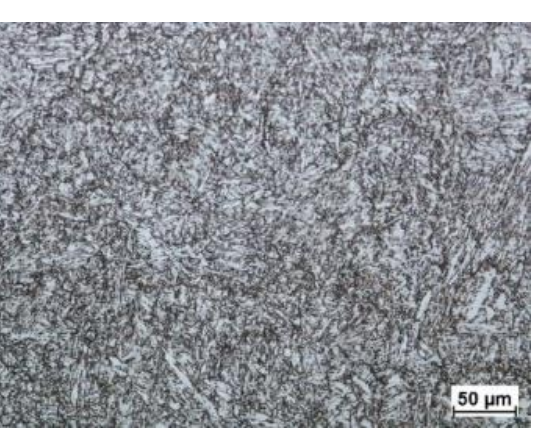

f

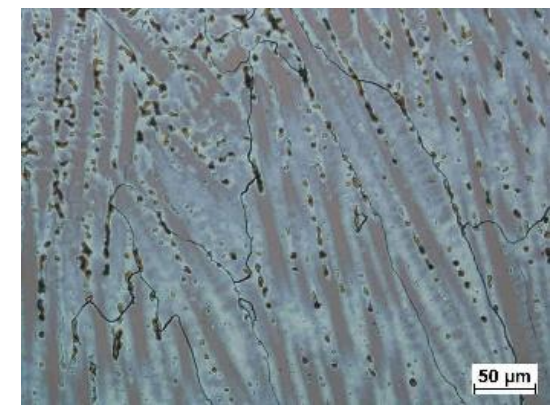

i

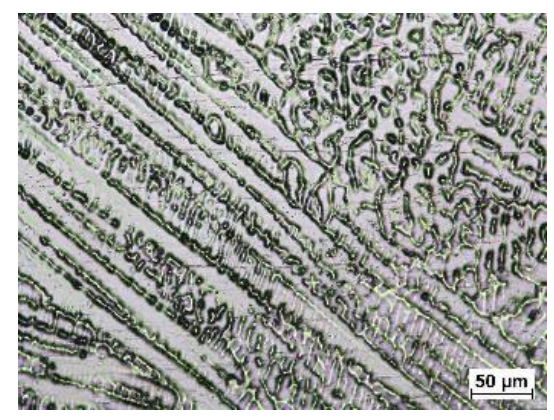

Figure 9 Microstructures of THOR®115 welded joint after electrolytic etching, a) base metal, b) heat affected zone, c) weld (in all cases tempered martensite for W CrMo91 filler metal), d) base metal (tempered martensite), e) heat affected zone (austenite-martensite, transition zone), f) weld (austenite). Cases d), e) and f) are for S Ni 6082 filler metal. g) base metal (tempered martensite), h) heat affected zone (austenitemartensite, transition zone), i) weld (austenite). Cases g), h) and i) are for EPRI P87 filler metal. 


\section{CONCLUSION}

On the basis of the aforesaid tests it was possible to come to the following conclusions:

1) Welded joints made of steel THOR®115, welded with GTAW in $5 G$ uphill position are characterized by high quality, which is confirmed by the results of destructive and non-destructive tests.

2) Weldability of $T H O R \otimes 115$ can be compared to other low-carbon martensitic steels no special precautions are required before, during and after welding compared to grade 91

3) Scheduled advanced microscopic tests and creep tests will enable a more detailed analysis of the welded joints and their industrial usability.

\section{ACKNOWLEDGEMENTS}

The authors wish to thank TenarisDalmine, Italy and Silcotube, Romania for providing THOR®115 base metal and ZELKOT, Poland for producing the welded joints and ŁUKASIEWICZ - Institute of Welding, Poland for all carried examinations.

\section{REFERENCES}

[1] CIPOLLA, L. et al. Conversion of MX Nitrides to Modified Z-Phase in 9-12\%Cr Ferritic Steels”. PhD Thesis. DTU Mechanical Engineering. Technical University of Denmark. 2010.

[2] SAWADA, K. Et al. TTP Diagrams of Z Phase in 9-12\% Cr Heat-Resistance Steels. ISIJ International. 2007, vol. 47, no. 5, pp. 733-379.

[3] LEPINGLE, V., LOUIS, G., ALLUĖ, D., LEFEBVRE, B., VANDENBERGHE, B. Steam oxidation resistance of new 12\%Cr steel: Comparison with some other ferritic steels. Corrosion Science. 2008. vol. 50. pp. 1011-1019.

[4] MINAMI, Y., YAMAMOTO, Y., ORTOLANI, M., MARIANI, P., PINT, B. Tenaris new high steam oxidation resistant. creep strength enhanced ferritic steel THOR®115". In Advances in Materials Technology for Fossil Power Plants: $8^{\text {th }}$ International Conference. Algavre: Albufeira, 2016, pp. 245-250.

[5] CEUCA, S., FERRARA, A., BAIETTA, S., MURARI, G. Extending the applicability range of CSEF steels for steam oxidation prone service condition. In THOR囚115 the Tenaris solution: MPA conference. Stuttgart: MPA, 2018, pp. 377-382.

[6] URZYNICOK, M., KWIECIŃSKI, K., SZUBRYT, M., SŁANIA, J. Application of new GMAW welding methods used in prefabrication of P92 (X10CrWMoVNb9-2) pipe butt welds. In 9th Liege Conference on Materials for Advanced Power Engineering. Liege: MPA, 2010, pp. 87-92.

[7] URZYNICOK, M., KWIECIŃSKI, K., SŁANIA, J. Analysis of problems occured during welding of new generation bainitic steel 7CrMoVTiB10-10 (T24). Archives of Metallurgy and Materials. 2009, vol. 58, no. 3, pp. 691-696.

[8] KWIECIŃSKI, K., URZYNICOK, M., ŁOMOZIK, M. Practical experience with welding new generation steel PB2 grade assigned for power industry. Archives of Metallurgy and Materials. 2011, vol. 56, no 1, pp. 37-45.

[9] PIKUŁA, J., ŁOMOZIK, M., PFEIFER, T. The Influence of Manual Metal Arc Multiple Repair Welding of Long Operated Waterwall on the Structure and Hardness of the Heat Affected Zone of Welded Joints. Archives of Metallurgy and Materials. 2012, vol. 62, no. 1, pp. 327-333.

[10] KRASNOWSKI, K. Influence of stress relief annealing on mechanical properties and fatigue strength of welded Joints of Thermo-Mechanically rolled structural steel grade S420MC. Archives of Metallurgy and Materials. 2009, vol. 54, no. 4, pp. 1059-1072. 